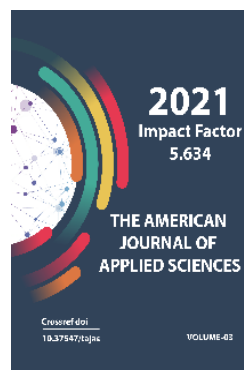

\title{
Material Handling Mechanisms In The Sewing Machine
}

\section{Tursunova Gulbahor Sharofovna}

Doctorant, Department Of Technology Of Light Industry, Bukhara Engineering Technological Institute, Uzbekistan

\section{Journal Website:} http://usajournalshub.c om/index,php/tajas

Copyright: Original content from this work may be used under the terms of the creative commons attributes 4.0 licence.

\section{ABSTRACT}

This article gives a detailed analysis of the material handling mechanism in a sewing machine. The construction and their working principle are presented.

\section{KEYWORDS}

Mechanism, material, rail, needle, lines, trajectory, engine, plate, conveyor, presser foot

\section{INTRODUCTION}

The material transport mechanisms of sewing machines are important mechanisms on which the quality and efficiency of the machine's workflow depend.

The material transport mechanism of the sewing machine is designed for periodic discrete movement of the materials to be sewn for a given stitch length. Movement of materials in the sewing machine is made periodically according to the cyclogram of the sewing machine. Typically, the movement of materials to be sewn: gear rack (slats), roller (roller), a special device (carriage, cassette, hoop, etc.) with clamped materials [1]. 


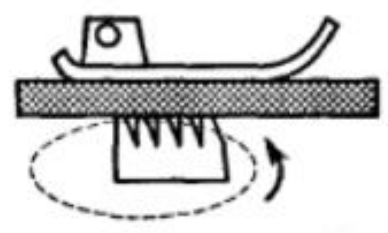

Fig. 1 Patterns of material transport on a sewing machine:

\section{a - by a rack and pinion conveyor; b - by a disc (roller) conveyor; c - frame}

The disc (roller) conveyor is used in sewing machines for processing leather and fur garments, as well as for performing auxiliary actions in sewing specialised machines.

Frame is used in machines that perform the stitching on a given program (buttonholes, tacking, etc.), as well as in universal programmable machines when performing embroidery.

In general-purpose sewing machines for stitching textile materials using rack and pinion type mechanism of the fabric engine, in which the movement of the material by the slat and presser foot.

The slat is offset both vertically and horizontally. When these two movements are correctly matched, the slat has an elliptical motion path. Each direction of movement the slat receives from the corresponding lifting and moving unit of the slat. Usually the material

advancement mechanism of the rack type has slave links (Fig. 2): the lever 2 with the rack; the

advancement lever 1; the lift lever 3. During the reciprocating motion, the advancement lever 1 reports horizontal movements, and the lift lever 3 reports lifting and lowering of the rack with the lever 2 . Consequently, the magnitude $L_{C T}$ of the rail 2 advancement depends on the range of reciprocating motions of the advancement lever 1 , and the lift of the rail - on the value of $y_{p}$ pumping of the lift lever 3 . Stitch length regulator and the return stroke of the rail are always kinematically connected with the advancement unit [2]. 


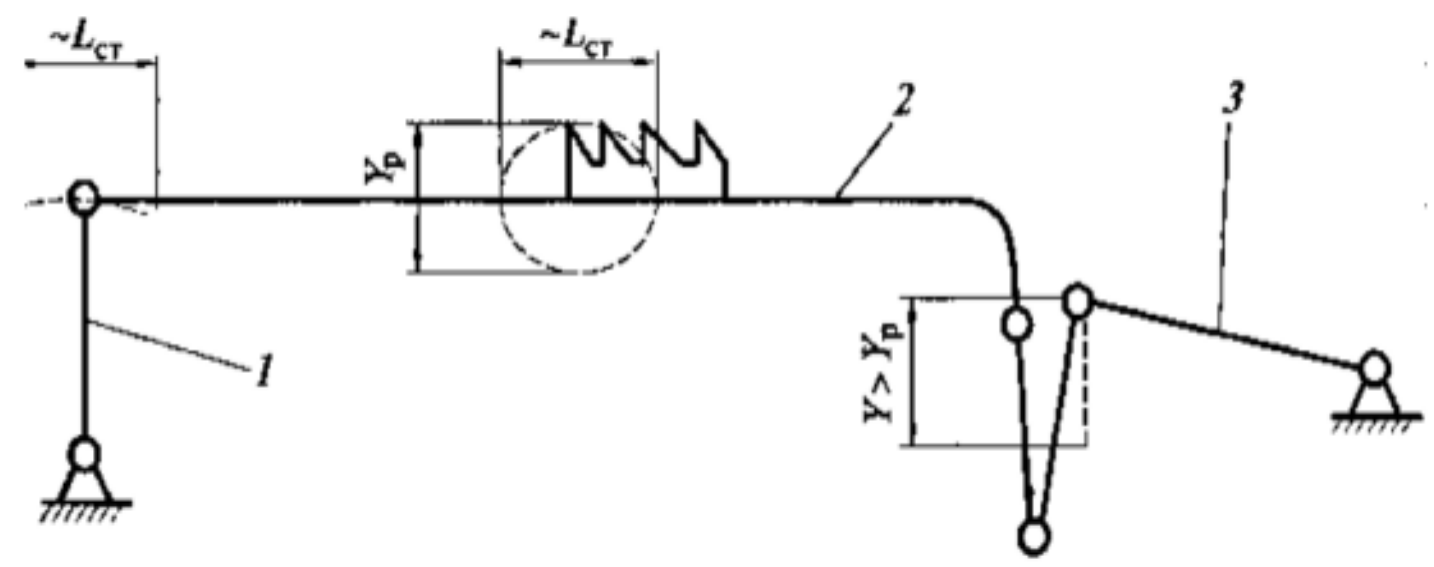

Fig.2 Toothed rack travel links

The direct moving element is the toothed rack 1 (fig. 3), which moves along the grooves of the needle plate where the packet to be machined is placed. The teeth of the rack, raised above the I-I level of the needle plate, press into the material at the appropriate moment of the work cycle and, capturing it, move it in the desired direction. After moving the material by

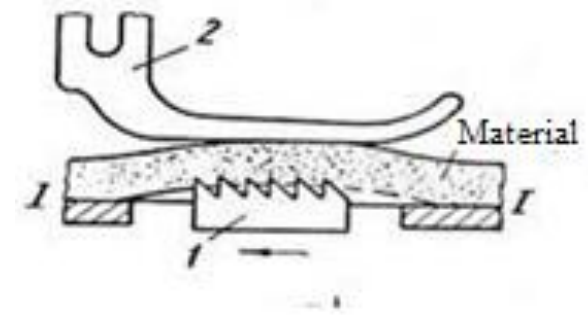

one stitch, the slats drop down below the upper plane of the needle plate and return to their original position.

On its own, the toothed fabric motor could not have accomplished any material movement if it had not been paired with a separate springloaded device that pressed the material against the needle plate.

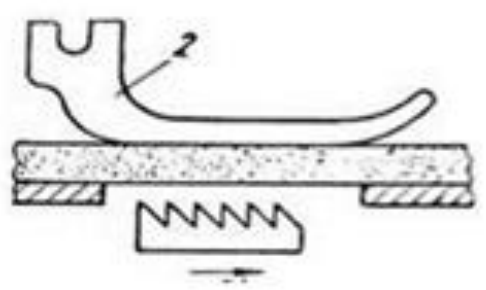

Fig.3 Principle of operation of the rail mechanism

The material is generally pressed down by a presser foot (or presser foot) 2 mounted on a rod that is pressed down by a spring. The pressure of the spring is adjustable.

Without the presser foot, the machine cannot be operated. During the working process, when the buttonhole is formed and then the buttonhole is tightened, the presser foot exerts pressure to secure the material to the needle plate. If the presser foot were not used, the fabric would rise with the needle and the eyelet loop would not be created.

Technologically the most desirable operation is the following: the teeth of the cloth motor rise 
vertically upwards, leaving the plane of the needle plate at a value $h$, and press into the material; the teeth of the motor move forward, in the feed direction; the plane of the tooth tips during the movement remains parallel to the plane of the needle plate; having completed the material movement, the cloth motor descends vertically downwards under the needle plate. The last stage is the return of the rail under the needle plate to its original position. Theoretically, the trajectory is a rectangle. In reality, to obtain such a trajectory requires a very complex mechanism $[3,4]$.

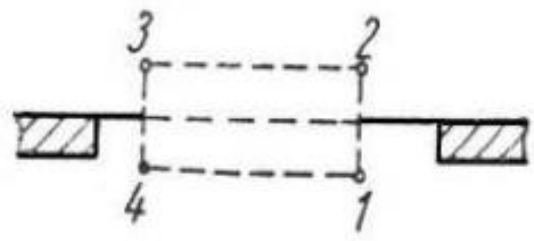

a) ideal;

b) actual
Therefore, there is a slight simplification of the scheme, forcing the cloth motor to follow an elliptical curve (Fig. 4). It is necessary to aspire that in the upper part the trajectory of tines was as close as possible to a straight line, and the initial and final sections were as steep as possible upwards, that corresponds to faster rise and fall of tines.

The material motor considered has a very significant disadvantage: on some materials it gives a 'fit' of the bottom layer in the pack.

\section{Figure 4. Rack tooth trajectory}

The fit is mainly due to the friction force of the top layer of the pack against the foot, which inhibits movement of this layer, as well as the deformation of the bottom layer when the rake teeth are pressed into it. With a large fit, the bottom layer of the pouch becomes corrugated. When stretching cross-linked materials, the seam may tear.

In this situation, it is better to transport the material with the slat and the needle moving together with the slat at the same time.

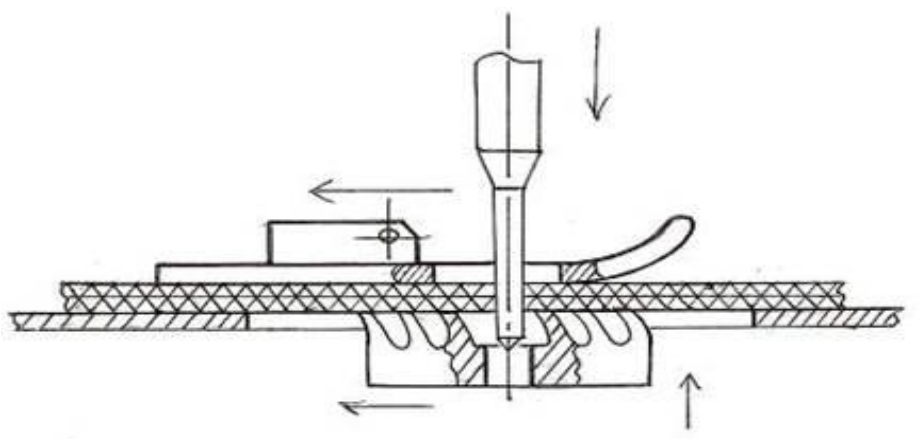

Fig.5. Scheme for transporting the semi-finished product with rail and needle 
To prevent the needle from breaking, its horizontal stroke speed is synchronized with the movement of the toothed rack. A hole is made in the rack to allow the needle to pass through, and a slit in the foot of the presser foot with a length slightly longer than the maximum horizontal needle stroke. In a number of cases, such a scheme gives a good result, and designers widely use this approach.

When joining lightly deformed materials, the desire to achieve well-tightened stitches leads to a change in their structure and, as a consequence, to shrinkage along the stitch line. If the stitches are formed on stretched fabrics, they can be very loose and the joint will be loose after leaving the foot, and when turned out, as the fabric makers say, a 'grin' will form, which is also unacceptable for aesthetic reasons. In addition, the spring loaded presser foot slows down the upper layer when moving the package to be sewn, so that it is somewhat stretched and the quality of the seam deteriorates.

These difficulties are solved by the use of a differential fabric motor in the machine design. This is a type of motor, which for the working process uses two bottom racks, at the same time and at the same height rising above the needle plate, but in a longitudinal direction (along the seam) have different magnitude stroke. The relationship between the magnitudes of these strokes is called a differential.

By setting the slats (each one different) horizontal movement, it is possible to create different conditions for the movement of the material in the area of the puncture, which allows it (the material) to stretch or compress, depending on the physical and mechanical properties and technological requirements [5].

The stitch pitch is determined by the stitch farther away from the operator. It is called the main rail. The nearer rail is called the differential rail. The value of its movement can be greater, less or equal to the stroke of the main rail.

If the strokes of both laths are equal, they move as one, their effect on the material is only the direct feeding of the workpieces under the foot. In this case, the differential is zero. Figure 6 a explains this position.

If the stroke of the differential toothed rail is greater than the movement of the main rail, then the differential feeds more material under the presser foot and thus eliminates the stretching effect. This is used when sewing soft materials (fig. 6 b).

If the stroke of the differential lath is less than that of the main lath, the fabric is stretched in the presser foot area. This differential is set according to the stiffness of the fabrics being processed (fig. $6 \mathrm{c}$ ).

In numerical terms the degree of differential is indicated by comparing the stroke of the additional rail with that of the main rail, taking the latter as one. 


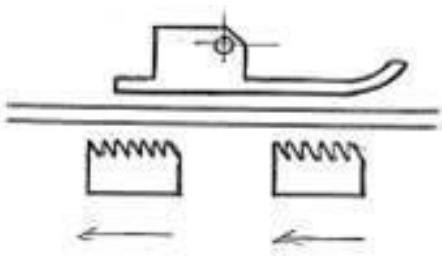

a

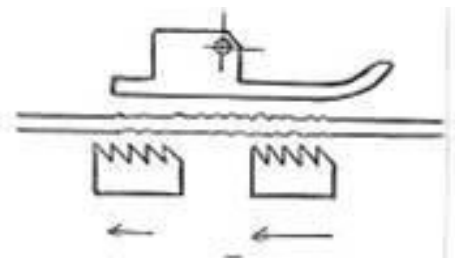

b

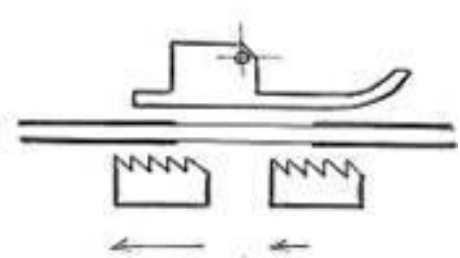

C

Fig.6. Diagrams explaining the operation of a fabric differential motor

For example, a differential of 1:2 means that the additional (differential) rail has twice the stroke of the main rail - a positive differential.

A ratio of 1:0.6 indicates that the stroke of the differential is less than that of the main rail negative differential.
Materials that are difficult to transport are moved under the presser foot by two toothed racks located at the top and bottom of the pack, which work by gripping, as with pincers, the workpieces to be sewn in the piercing area (Fig. 7).

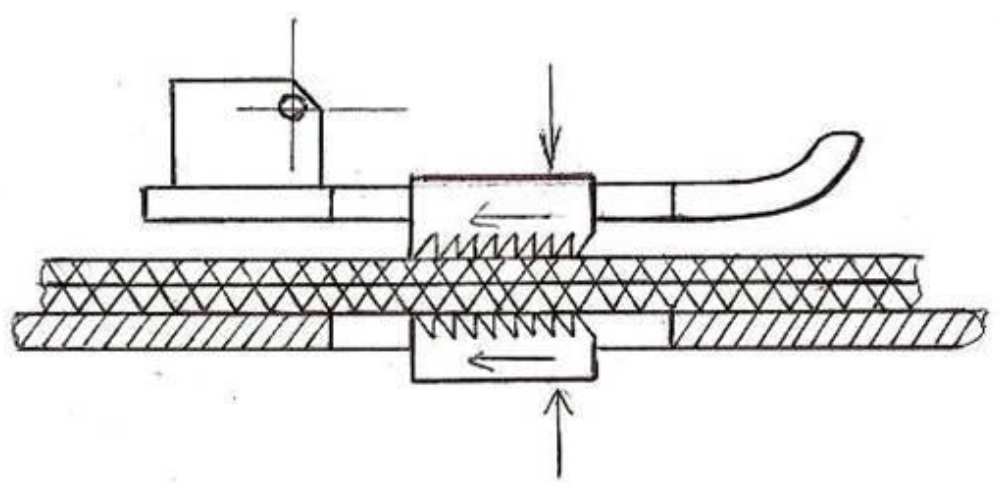

Fig.7. Conveyor unit with upper and lower advancement rails

During the transport the presser foot is raised. When the movement is completed by one step (per stitch), the foot is lowered and holds the pack against the needle plate.

The same mechanism can also be used in cases where it is necessary to ensure a predetermined fit of the layers in the pack [6].

This is accomplished by setting different horizontal movements for the top and bottom rails. Leather stitching machines use a roller instead of a foot. It can have a forced rotation, which improves the transport process. A double roller conveying option is also possible, this allows better conveying of the material on steep turns.

For the most difficult variants of sewn packages (many layers, transversal seams, wide processing band) a puller pulley unit is used, which is installed directly in the sewing area immediately behind the presser foot. The pull roller drive is synchronised with the rotation of the machine's main shaft and is often controlled electronically. The roller 
pressure on the material is also controlled in the latest designs, so that it can be automatically adjusted as required when the pack thickness changes, e.g. when cross seams are crossed.

\section{REFERENCES}

1. Ganchini Shukhratzoda, A.Djuraev, M.A.Mansurova, S.Dj.Mukhamedjanova, "Design development and mathematical model of vibrations of plates of the tension regulator of the tension needle sewing machine"/ International Journal of Advanced Research in Science, Engineering and Technology. Vol. 6, Issue 7, July 2019, p.10208-10210.

2. Bozorova Farida, Mukhamedjanova Sabrina "Simulation Of Forced Vibrations Of The Elements Of A Sewing Machine's Compound Foot" Acta of Turin Polytechnic University in Tashkent: Vol. 10 : Iss. 3 , Article 5.p.22-25.

3. A.Djuraev, K.Yuldashev, C.Dj.Muxamedjanova "Calculation of the power of the undulating surface of the screw conveyor for cleaning lint" Acta of Turin Polytechnic University in Tashkent: Vol. 10 : Iss. 4 , Article 3.p. 59-64

4. Djurayev A., M.A.Mansurova, G.Sh.Tursunova, M.X. Shirinova "Effect of the Stitch Length on the Breaking Load of Stitches of Sewing Products" International Journal of Advanced Research in Science, Engineering and Technology Vol. 6, Issue 9 , September 2019.

5. Juraev Anvar and Rajabov Ozod, "Analysis of the interaction of Fibrous Material with a Multifaceted Grid of the cleaner", International Journal of Recent Technology and Engineering, Vol. 8, No. 1, (2019), pp. 2661-2666.
6. Djurayev A., Sh. Daliev, A. Zukhriddinov "Development of the resource-saving structure of the section of small purification of fiber material" International Journal of Advanced Research in Science, Engineering and Technology Vol. 6, Issue 2, February 2019 p.8080-8083. 